\title{
LA EUROPEIZACIÓN DE ESPAÑA DESDE LA CULTURA Y LAS CATEGORÍAS DEL JUICIO. REFLEXIONES EN TORNO A GANIVET, UNAMUNO Y ORTEGA
}

Francisco Javier Ochoa de Michelena*

\section{RESUMEN}

España suele tenerse hoy en día por un país plenamente europeo. Esta consideración no estaba, sin embargo, tan extendida unas pocas décadas atrás. ¿Cómo llegó España a ser europea? ¿Cómo accedió a la dimensión cultural del espacio europeo? ¿Cambió sus actitudes mentales? ¿Escogió otras tradiciones? ¿Modificó su ejercicio del juicio? ¿Ajustó su producción cultural a los requerimientos de "lo europeo"? Este ensayo pretende abordar estas cuestiones con la ayuda de las ideas apuntadas por tres destacados pensadores españoles -Ganivet, Unamuno y Ortega y Gasset- que específicamente se plantearon el problema de la adecuación, o no, de España a la Europa de la cultura.

\section{PALABRAS CLAVE}

Europa, España, cultura, Ganivet, Unamuno, Ortega y Gasset, juicio, producción cultural, transición.

\begin{abstract}
Spain is nowadays said and known to be fully European. This common acknowledgement was, nevertheless, not that straightforwardly assumed only some decades ago.

How, if at all, did Spain become European in cultural terms, that is, how did its mental attitudes, its elected traditions, its exercise of judgement or its cultural production change over the XXth century? This essay considers the issue in the light of the ideas brought forward by three Spanish thinkers -Ganivet, Unamuno and Ortega y Gasset- who specifically tackled the question of Spain's cultural adequacy -or particularity in relation- to Europe.
\end{abstract}

\section{KEY WORDS}

Europe, Spain, culture, Ganivet, Unamuno, Ortega y Gasset, judgement, cultural production, cultural transition

\footnotetext{
* Profesor de la Facultad de Ciencias Políticas y Sociología de la Universidad Complutense. Artículo ganador de la V edición de los Premios de Ensayo Breve "Fermín Caballero", convocados por la ACMS
} 


\section{INTRODUCCIÓN}

Este ensayo se propone como una reflexión en torno a la cuestión de la europeización de España y, más específicamente, a la adecuación de la vida cultural española a la dimensión y modalidades de la Experiencia cultural europea. Toma como punto de partida las consideraciones que sobre la "especialidad/europeidad española" hicieron Ángel Ganivet, Miguel de Unamuno y José Ortega y Gasset.

Este escrito procede, no sin algo de humor, por la senda del llamado "ensayismo español" ${ }^{1}$ y acude, para avalar sus argumentos, a las exposiciones que sobre la obra de esos tres autores han hecho destacados ensayistas españoles: José María Beneyto, Juan Marichal, Pedro Laín Entralgo, Julián Marías, etc. (véase la bibliografía). Así mismo, propone una categorización del Juicio como matriz conceptual desde la que evaluar la aportación de los tres autores a la reflexión sobre la "europeización cultural de España". Las cuatro categorías del juicio consideradas son: el juicio histórico, el reflexivo, el determinativo y el particularista. ${ }^{2}$

Empezaremos con la crisis del 98 para situar ya sea la obra de los tres autores aquí analizados como el llamado "problema de España".

\section{APROXIMACIÓN A LA GENERACIÓN DEL NOVENTA Y OCHO}

\section{Disastro, ma non troppo}

Quizá convenga empezar situando, someramente, la Generación del noventa y ocho en su contexto, en aquel contexto dramáticamente denominado El Desastre.

Pues bien, puede concederse que tal Desastre se produjo pero sólo para añadir que su alcance en lo cotidiano fue escaso, acaso insignificante. No se trata aquí de recordar la sofística tesis del historiador Jesús Pabón sobre la planetaria extensión del desastre, extensión que relativizaría el drama español al comprobarse que los portugueses tuvieron el suyo con la Crisis del Ultimátum, los franceses con Fachoda, etc. y los españoles con el Tratado de París. Sin duda se produjo en esos años una reordenación del orden internacional en beneficio de las naciones anglosajonas y detrimento de las viejas y latinas naciones imperiales. Pero lo del mal de muchos, aunque se haga tesis historiográfica, sigue siendo consuelo de tontos. ¿Pero existió ese mal?

Sí, España tuvo que renunciar a sus posesiones ultramarinas y a aquellas empresas exteriores en las que torpemente había querido embarcarse en la segunda mitad del siglo XIX (recuérdense las aventuras de O'Donnell) y se vio así reducida, en la percepción de algunas de sus elites, a su dimensión peninsular: tuvo que mirar hacia dentro, a sí misma. Y en este contemplarse, que para algunos fue descubrimiento de esa España, se situaría la Generación del noventa y ocho. 
"1898 no fue ni detonante ni fecha bautismal de la Generación del 98"

Pero esta llamada generación ya había iniciado, e incluso en el caso de Ganivet concluido, su andadura en torno al "tema de España" antes del 10 de diciembre de 1898. En torno al casticismo de Unamuno se publicó en el año 1895, y, antes de su suicidio el 29 de noviembre de 1898, Ganivet ya había dejado escrito: "Si la fatalidad histórica no nos hubiese puesto en la pendiente en la que nos puso [la de la empresa colonial], lo mismo que la fuerza nacional se transformó en acción, hubiese podido mantenerse encerrada en nuestro territorio, en una vida más íntima, y hacer de nuestra nación una Grecia cristiana". Esta cita no sólo resume muy bien el pensamiento de Ganivet sino que indica que la pérdida de la posición internacional de España ni desencadenó, ni intensificó en estos autores "el dolor de España"... Ganivet habría podido incluso interpretar la caribeña derrota como una circunstancia esperanzadora.

Por otro lado, como señala Julián Marías, el Desastre no hizo tambalear un régimen, el de la Restauración, que atravesaba por entonces su periodo de Regencia, ni minó la legitimidad del sistema caciquil y de la llamada "oligarquía parlamentaria". Es más, "la pérdida de Cuba, Puerto Rico y las Filipinas no significó quebranto económico para España; más bien al contrario, la economía española mejora sensiblemente en los primeros años del siglo XX" (Marías, 1996: 388). La magnitud del "desastre nacional" en el orden cotidiano fue pues limitada, aunque quizá no lo fue la percepción del mismo por parte de determinadas mentes, las usualmente adscritas a la Generación del 98.

"La invención orteguiana de la Generación del 98... y su nacionalización"

Pero quisiera atreverme a decir más: lo que en verdad se magnificó fue la percepción que de la obra de los autores de la Generación del 98 tuvieron los miembros de la Generación del 14 y las autoridades españolas desde principios del siglo XX hasta la República.

Cabe, en efecto, sostener que la Generación del 98, primero, es una construcción ex post interpretada a través de los ojos de Ortega ${ }^{3}$ (y en menor medida de Azorín y Azaña) y, segundo, ha sido un elemento importante en lo que podríamos denominar "la construcción y difusión del nacionalismo español". Como señala José Álvarez-Junco, tras permanecer a lo largo del siglo XIX limitado a unas elites que se debatían entre un nacionalismo de corte liberal y otro tradicionalista, con el inicio del siglo XX se verificaron esfuerzos coordinados por parte de las autoridades por difundir el sentimiento nacionalista en la generalidad de la sociedad española, en un programa que podría enmarcarse en el tiempo entre la celebración del tercer centenario del Quijote (1905) y la II República pasando por la exposición Universal de Barcelona de 1929. Así, como señala José María Beneyto: "Será sobre todo con el traslado de los restos de Ganivet desde Riga a Granada en 1925, durante 
la Dictadura de Primo de Rivera, cuando la figura del "algo olvidado" autor del Idearium Español, se convierta en un símbolo nacional del "dolor de España" (1999: 69, el subrayado es mío).

"Algo olvidado", y, en la suerte, recuperado, por las autoridades seguramente, aprovechando la interpretación que Ortega hizo de la Generación del 98 como símbolo de la "europeización de España". Un símbolo claramente "nacionalizable y nacionalizado" para beneficio de unas autoridades en pos de una nación presente y de una intelectualidad en pos de una presencia nacional, cuando no europea...

\section{"La Generación del 98 y la política"}

Antes de abordar la interpretación orteguiana de la Generación del 98 conviene referirse a uno de los defectos que habitualmente se han venido achacando a los autores de dicha Generación. Fue quizá Azaña quien con más saña les atribuyó el defecto de "no morder la acción", de no participar en la acción política. Se trata de una acusación injusta por falsa y retroactiva. Falsa porque conocidos son, por ejemplo, los muchos e infructuosos esfuerzos que hizo Costa por difundir a través de tantos empeños corporativistas sus ideas y proyectos; como conocidas son las posiciones públicas que adoptó Unamuno a lo largo de su carrera y casi hasta el día de su muerte. La idea, que aún puede leerse en los libros, de que Unamuno se retiró de la vida pública tras su enésima crisis religiosa en la década de los 1910 ha demostrado ser falsa. Es cierto que su presencia pública se desfiguró tras su destierro a Francia en 1924 como más cierto es que fue diputado de la Constituyente de 1931. La figura de Ganivet, desaparecida a los treinta y tres años tras escribir no una sino dos ambiciosas tesis doctorales ${ }^{4}$ y varios libros, opositar sin éxito a cátedra (trance en el que fue compañero de Unamuno) pero conseguir acceder a la carrera consular, podría encajar mejor en la acusación de Azaña pero a fuer de ser anacrónica: de aplicar una (in-) justicia retroactiva.

La situación de la intelectualidad en España entre 1909 y 1936 no es comparable a la que conocieron con anterioridad los autores del 98. Primero por sus respectivas mentalidades: los autores del 98 pueden calificarse de tardo-románticos mientras que los del 14 son, por así decir, 'progresistas'. Y no quiere decir esto que la forma mentis de los primeros excluya la acción para centrarse sólo en la contemplación y que la conciencia de los segundos haga la exclusión contraria. ${ }^{5}$ Ambos compaginan acción y contemplación, y si bien es de suponer que ninguno se vio en la obligación de conferir mayor importancia a una de las actividades sobre la otra, sí es cierto que una mentalidad tardo-romántica tendrá más tendencia a valorar la vis contemplativa frente al progresista, como también es cierto que el tardoromántico hará de la contemplación ejercicio espiritual mientras que el progresista seguirá con mayor agrado la máxima de Catón: "Numquam se plus agere quam nihil cum ageret, numquam minus solum esse quam solus esset". Pero lo que importa, y se trata del segundo elemento diferenciador, es el contexto: éste varía, de 
suerte que el que conocen los de la Generación del 14 (y, por su longevidad, Unamuno) valoriza más la acción de sus intelectuales frente a la atención que pudo prestar la España de Cánovas a sus pensadores. No olvidemos que Costa, a pesar de sus esfuerzos, no llegó a diputado y que Azaña fue Presidente de la República y Ortega e, insisto, Unamuno, diputados de la Constituyente. Cambia el contexto, por muchos motivos, entre ellos, porque el régimen de la Restauración no entra en crisis abierta hasta 1909 (Semana Trágica, condena de Ferrer); porque el fenómeno de los "intelectuales" si bien se forma en España, como en Francia, en torno a 1898 no alcanza presencia efectiva en España sino con posterioridad, precisamente porque si en la Francia del 98 ya había una "nación para una movilización" en España no habría, grosso modo, nación hasta los años 20 ni movilización hasta los años 30 . Así, en los años 20, la nación "sin partidos" (prohibidos en la Dictadura de Primo de Rivera) destierra a Unamuno (1924) y celebra con fastos la repatriación del cuerpo de Ganivet ${ }^{6}$ (1925) sin duda, porque por distintos motivos confiere relevancia a un "elemento intelectual" cuya posterior participación en la caída de la Monarquía y en el liderazgo de la República (la "nación movilizada") no será menor. Recordemos, por ejemplo, que la España oficial de Cánovas no hizo caso alguno a las peticiones de Unamuno con motivo de los procesos de Montjuïc.

"El supuesto empeño europeizador de la Generación del 98"

Un elemento que propicia la nacionalización de la Generación reside en la interpretación que Ortega hizo de la misma como una primera etapa en la reflexión en torno no tanto a España como a la europeización de España. Una primera etapa a la que seguiría una segunda a la que pertenecería el propio Ortega. Es decir, Ortega interpreta retroactivamente la Generación del 98 atribuyéndole dos características que en verdad pertenecen al propio Ortega: 1) el genérico empeño por europeizar España entendido según 2) el orteguiano perspectivismo.

La idea de europeización de Ortega es la de adecuación a los tiempos culturales o, dicho en términos más generales, a los ritmos científicos de Europa para poder así, desde la misma "altura de miras" que el resto de Europa, aportar una visión española del mundo.

Así, Ortega dirá (en 1940) de Ganivet y Unamuno: "Cuanto más tiempo pasa, más levantada parece la hazaña que estos dos hombres y otros de su generación peninsular cumplieron, haciendo universal el horizonte de la cultura española. Desde entonces el escritor y profesor en España asisten a la vida intelectual del mundo entero".

Porque para Ortega su "España es el problema, Europa la solución" (dicho en 1910) significaba sincronizar España con una Europa entendida como sinónimo de modernidad racionalista: "Europa = Ciencia", vino a decir. Ya en 1922 aseguraba que: "los intelectuales españoles [han] conquistado en la estimación de los demás pueblos un puesto para España que desde hacía siglos no ocupaba". Ortega quería 
"hacer universal el horizonte de la cultura española" (1940), hacerla partícipe del pensamiento racionalista (arreligioso y optimista) moderno.

Y es así como con posterioridad, y como lo atestiguan, por ejemplo, los libros de Marías y de Juan Marichal, se ha interpretado la vida intelectual española del primer tercio del siglo XX como un afanado empeño de los intelectuales españoles por estar a "la altura cultural de los tiempos europeos". Un empeño realizado en tres etapas, las llamadas Tres Generaciones $(98,14$ y 27) que desde la inicial postergación periférica habría alcanzado una brillante presencia en la vida cultural europea. Así, para Marías: "La Generación del 98, sea cualquiera su opinión sobre la $<<$ europeización $>>$, la realiza de un modo real al poner a España a la "altura del tiempo". [...] por supuesto, las instituciones no alcanzan ese nivel; pero en las "cimas", en la creación intelectual y literaria, desaparece el desnivel: estos autores, y los de primera fila de las generaciones siguientes, "no son en ningún sentido inferiores' a los equivalentes de los otros países europeos." (1996: 391-392, el primer y último subrayados son míos, los dos intermedios del autor). O también, Marichal que, con su orteguiano (y orteguista) entender de esa historia "desarrollista" de la intelectualidad española, estima que el relativo éxito internacional de la Rebelión de las masas marca un hito, sino el hito, en este desarrollo toda vez que el libro "mostró que un pensador español estaba a la 'altura europea de su época' y podía exportar tras el Pirineo ideas concebidas en tierra española" (el subrayado es mío). Había conseguido ofrecer la interpretación española del mundo; incorporarse al pensamiento moderno de Europa con una filosofía estrictamente española. Una filosofía del estar en el mundo como español. Esta interpretación de la vida intelectual de ese período como un esfuerzo por asomar desde la periferia la cabeza en el escenario cultural de Europa hasta convertirse en actor de la comedia cultural continental, adolece de varios problemas. Se me ocurren de entrada, por ejemplo, dos; dos que llevan nombre: Pérez Galdós y Echegaray.

Subyace a esta interpretación de las Tres Generaciones que antes de éstas no había nada que estuviera a la altura (y no ya solo en el terreno de las letras). Ahora bien, ¿no cabe pensar que, a pesar de sus defectos, Pérez Galdós es literariamente superior a los Machados, Azorines y compañía? Por otro lado, el que sí estuvo bajo los focos del escenario literario europeo fue un tal Echegaray, digo "un tal", porque ya casi nadie lo recuerda y absolutamente nadie lo lee; y mientras los suecos en nombre de la humanidad le agasajaban, Valle-Inclán le llamaba "viejo idiota". Nos viene a la mente otros nombres, en el terreno de la pintura, que poco (Dalí con la del 27) o nada (Picasso, Miró, Gris) tuvieron que ver con esas Generaciones y que ocuparon bien pronto su lugar en el escenario europeo de las vanguardias artísticas.

Pero lo más problemático de esta interpretación es que presume que Ganivet, Unamuno y compañía se afanaron, como hizo Ortega con sus (si se permite la expresión) "naciones unidas de los prólogos" a la Rebelión de las masas, en que sus libros fueran traducidos al alemán, sobre todo, y al resto de idiomas, también. Dudo 
que Ganivet y Unamuno respondan a la idea orteguiana de sincronización y menos aún a la de participación en el debate cultural europeo. Porque, en efecto, la idea que Ortega tiene de Europa, más allá de la ecuación "Europa = Ciencia", es la de un espacio público en el que fluyen ideas y creaciones: Europa sería como una suerte de gran Ateneo continental que atiende a los más brillantes. Bien, la idea de Europa de Ganivet y de Unamuno no es ésta.

Otro problema que subyace a la interpretación orteguiana del desarrollo intelectual español del primer tercio del novecientos es el que viene constituido por el latente complejo de inferioridad respecto a "Europa": el que quiere asomarse desde la periferia, se entiende periférico. Ortega insiste en esta idea hasta deshacer cualquier sombra de duda sobre su eventual interpretación de la "europeización de España". En 1917 dijo: "Tenemos que ensancharnos las cabezas para dar a nuestras ideas dimensiones de mundialidad. La España de villorio no nos interesa: queremos y creemos posible una España mundial". No creo que Unamuno con su "iQue inventen ellos!" o Ganivet con su "Noli foras ire, in interiore Hispanitas habitat veritas" se sintieran en modo alguno periféricos (entiéndase, podían sentirse acaso relegados de un escenario europeo que obviaban al no tener ningún afán continental de protagonismo).

"Las etapas del desarrollo intelectual. ¿Un manifiesto orteguista?”7

Lo sorprendente es que esta visión orteguiana se haya extendido a todo el siglo $\mathrm{XX}$ (y lo que va de XXI) en las interpretaciones de los orteguianos, principalmente de Marías, cuyo libro Ser español expresa con todo patetismo (uso esta palabra de acuerdo con la única e inofensiva acepción que le da el DRAE) este complejo de inferioridad. Así en Ser español (2001), Marías define la pretérita "anomalía hispánica" como la "falta de ideas", concibe la historia como transmisión generacional de un patrimonio acumulativo y "vinculante" (desarrollismo intelectual), afirma literalmente que "Ortega es el principal filósofo del siglo XX" (del "mundo mundial", entiéndase); de la obra, precisamente, de Unamuno dice: "es considerada hoy inequívocamente como una de las producciones de mayor interés en la filosofía del primer tercio del siglo XX" y remata la faena, tras lamentar una supuesta crisis intelectual en la Europa de hoy en día, con un: "En España encuentro motivos para confiar en que la mente europea salga adelante". Ante semejante estocada, aquellos europeos que por la suerte (de varas) han dejado de ser actores (ante el anómalo español) para convertirse en asistentes al Ateneo continental de las ideas cuya esencia preserva el antiguo periférico, no podrían sino exclamar: Unbelievable! (el humorístico británico), Unglaublich! (el teutónico alemán), C'est pas vrai! (el desconcertado francés), Não pode ser! (el portugués, también llamado el "inglés sin sentido del humor") o Non ci posso credere! (el italiano, más ambiguo en la forma y demasiado irreverente en el fondo). Esta frase final de Julián Marías tiene claras resonancias: no me referiré a las más obvias para todos nosotros 
(aquello de la "reserva espiritual de Occidente", o el orteguiano "promontorio espiritual"), sino a Feodor Dostoievsky quien aseguraba allá por la década de 1860 que la salvación de la materialista Europa estaba en la cristiana Rusia, la de la Iglesia griega, ortodoxa y moscovita ${ }^{8} \ldots$ ¿No era Ganivet el que se refería a la España ideal como "una Grecia cristiana”? ¿Habremos cerrado, según la expresión de moda, un "bucle melancólico": el "bucle melancólico de los periféricos"? ¿De Marías a Dostoievsky, y Ganivet tira porque le toca? Le toca, en efecto.

\section{GANIVET Y LA “GRECIA CRISTIANA"}

En su (primera y rechazada) tesis doctoral (de 1889), ${ }^{9}$ Ganivet establece una distinción entre filosofía científica o académica y filosofía vulgar, viviente o real, entendida como "pensamiento colectivo" de un pueblo. Distinción que construye sobre la idea de que "como las sociedades carecen de conciencia reflexiva, no existe la posibilidad de una antinomia entre las ideas y las manifestaciones externas, y se puede afirmar que [en éstas] existe una revelación del modo de ser interno del sujeto colectivo que las produjo". Esto significa que para Ganivet la filosofía dirige efectivamente la vida de los pueblos. Esta filosofía puede o no ser síntesis de su rama científica y de la vulgar (que no ordinaria). Estima, sin embargo, Ganivet que ambas filosofías se encuentran distanciadas en España de suerte que el pueblo se rige exclusivamente por la vulgar. Una filosofía popular cuya característica definitoria sería un "escepticismo" que engendra "una ausencia de ideales normativos" de actuación. Un "escepticismo social" que delata un "periodo de postración intelectual" que se "traduce en la práctica por un lamentable indiferentismo". El "escepticismo" no se equipara en Ganivet con el sarcástico ejercicio de la duda sino con la "abulia", palabra que también usa para identificar la situación española.

Ganivet resume su diagnóstico y propone el remedio con estas palabras: "Así como la perturbación de nuestra sociedad es debida a varias causas que se condensan en una sólo: el escepticismo, así también todo plan reformador debe partir de un solo punto céntrico: la acertada educación filosófica [del pueblo]". Y entiende que esta "acertada educación" ha de remitirse a unos valores antemodernos: los de la escuela de Diógenes: el cinismo, entendido como filosofía de la "crisis existencial", como un esfuerzo por ser "nada menos que todo un hombre" más allá de unas convenciones que estarían tambaleándose y resguardados en un ascetismo de las cosas verdaderas, alejado del materialismo de la ciencia y postrados ante la magnificencia de la Naturaleza.

Ganivet, en efecto, desprecia lo moderno, es decir, todo lo que Europa representa y apuesta por la recuperación-consecución de "un periodo español puro". Esta "restauración de la vida entera de España no puede tener otro punto de arranque que la concentración de todas nuestras energías dentro de nuestro 
territorio. Hay que cerrar con cerrojos, llaves y candados todas las puertas por donde el espíritu español se escapó de España para derramarse por los cuatros puntos del horizonte".

¿Ganivet europeizador? Así quisieron interpretarlo los orteguianos. Recordamos la frase de Ortega de 1940 arriba mencionada: Ganivet y Unamuno "[hicieron] universal el horizonte de la cultura española". Pero señalemos también que el mismo Ortega dejó escrito en 1910 que era poco deudor de Ganivet "porque éste no logró elevarse a un punto de vista sobrenacional y sus opiniones adolecen de una visión provinciana del universo". Acaso en 1910 el concepto Generación del 98 aún no había cuajado, y menos aún el concepto europeizante de la Generación, y sin duda Ganivet aún no había sido reivindicado, y cómo, por la dictadura de Primo de Rivera.

Porque, ¿en qué consiste esa recuperación de lo español que propone Ganivet? En el Idearium español (1897) el mencionado cinismo se "españoliza" (es un decir) adquiriendo los tonos del (muy romano, y poco hispánico) senequismo; un senequismo aderezado con mucho de "espíritu territorial" (jsí!, el que marca la tierra) y algo de "espíritu nacional” (¡no!, el que marca la raza) ${ }^{10}$. Ganivet acomete una suerte de arqueología de aquella alma española extraviada en sus conquistas y que se propone recuperar condensándola en una palabra: el misticismo.

Esta idea sobre la esencia mística, estoica o cínica, de corte senequista, no se corresponde, claro está, en nada a la psicología del español, seguramente no al de nuestros días, probablemente menos aún al de finales del siglo XIX, y apenas al anterior. De hecho ya en 1902 Rafael Altamira en su Psicología del pueblo español deshizo los argumentos principales del "español puro" de Ganivet: el misticismo no es en España tendencia genuina (ni originaria ni "originante"). Pero lo que sorprendente es que el propio Ganivet está de acuerdo con esta negación: entiende que la historia de España no ha sido nunca genuinamente "española": "Hemos tenido después de períodos sin unidad de carácter, un período hispano-romano, otro hispano-visigodo y otro hispano-árabe; el que sigue será un período hispanoeuropeo e hispano-colonial... Pero no hemos tenido nunca un período español puro, en el cual nuestro espíritu constituido ya diese sus frutos en su propio territorio". Lo hispano-español no ha existido; es sólo, para Ganivet, una potencialidad que debe llegar a manifestarse: la España soñada en la que se realice la "Constitución ideal" del espíritu hispano-español; un espíritu del todo ajeno a la obra histórica de España, a lo real pero "desalmadamente" (sin atender a su verdadero espíritu) hecho por los españoles.

"Los juicios en el pensamiento de Ganivet"

El "juicio histórico" en Ganivet no es tal pues no se remite a hechos, sino a supuestas esencias. Se trata acaso de un juicio arqueológico en pos de quiméricas esencias soterradas tras excesivos episodios de "alteración"; un juicio que da pie a 
otro político a favor de un periodo de "ensimismamiento" 11 gracias al cual alcanzar la perfección espiritual. Palabra de Ganivet: "Nuestro Renacimiento quedó incompleto por la desviación histórica a la que la fatalidad nos arrastró [el ser siempre hispano-algo pero nunca hispano-español]; pero como la fuerza propulsora está en la constitución natural étnica o psíquica que los diversos cruces han dado al tipo español, tal como existe hoy, tenemos que confiar en el porvenir".

¿Y sus juicios reflexivos? Para quién decía (con ¿mística afectación?): "No sólo sé que se me obstruye el camino, sino que yo mismo me dedicaré a obstruírmelo con objeto de no ir a ninguna parte", sorprende que pudiera también decir: "Hay que sacrificar la espontaneidad del pensamiento propio, hay que fraguar 'ideas generales' que tengan curso en todos los países para aspirar a una influencia política durable. Nosotros, por nuestra propia constitución somos inhábiles para estas manipulaciones y nuestro espíritu no ha podido triunfar más que por la violencia". De esto a convertir la España-españolizada en paladín de la salvación espiritual de una Europa presa de la modernidad con sus materialismos, industrialismos, socialismos, democracias, liberalismos y demás desquiciamientos, sólo hay un paso. Ganivet lo dará, eso sí: sin la brillantez de Dostoievsky ${ }^{12}$.

Se trata, pues, de un juicio que se proyecta en lo universal, en este caso Europa, pero ¿se trata de un juicio reflexivo capaz de ser compartido porque anticipa el deseo de ser compartido, o se queda en un juicio particularista encerrado en su propia complacencia?... Basta responder a esta pregunta: ¿cómo pudieron algunos españoles tomarlo en consideración? No cabe duda, en este sentido, que resulta difícil cimentar una sociedad sobre el misticismo..., a menos que se trate de una sociedad monástica..., para lo cual se necesitan muchos monjes. Sólo así, en la quietud de lo monástico puede conseguirse simultanear el individuo monádico con la sociedad orgánica que propone Ganivet. Pero en verdad no vemos tal sociedad y, a duras penas, vemos más de un monje: eso sí, más en "esencial potencia" que en biográficos hechos..., el propio Ganivet y su identidad.

Y su idea de ¿los juicios determinativos? Rechaza aplicar lo europeo y ese su afán por el dominio técnico de la naturaleza; pero de puertas adentro: "cuando todos los españoles acepten, 'bien que sea con el sacrificio de sus convicciones teóricas', un estado de derecho fijo, indiscutible y por largo tiempo inmutable, y se pongan unánimes a trabajar en la obra que a todos interesa [y que Ganivet no define], entonces podrá decirse que ha empezado un nuevo período histórico". Es decir el juicio determinativo, en principio extrínseco a la persona que lo ejecuta, se convierte en Ganivet en juicio determinativo identitario, existencial, el misticismo como ley. Basta añadir que Ganivet apoyaba el autoritarismo, la dictadura como vía para realizar la esencia de lo hispano-español (acabamos entendiendo por qué la Dictadura de Primo de Rivera reivindicó la figura de Ganivet).

Acaso no merezca la pena recapitular los rasgos del patético pensamiento de Ganivet (y uso ahora la palabra 'patético' como un anglicismo, es decir, en el sentido coloquial que recoge el diccionario Oxford). Digamos, de momento, que no 
buscó anticipar el diálogo con los demás ni el acuerdo sobre el mundo. Sin embargo, sí llegó a dialogar con alguien, con Unamuno ${ }^{13}$, pero como diría el castizo: "Don Miguel es otro que tal baila".

\section{UNAMUNO Y LA ESPAÑA PROTESTANTE}

En En torno al casticismo (1895) Unamuno se propone ahondar en la intrahistoria española, es decir, en los hechos vivos frente a los sucesos históricos, en una distinción idéntica a la de Ganivet entre "espíritu español puro" (lo sustancial) y "obra histórica de España" (lo accidental). Y, aunque se propone hacerlo mediante la cultura y la ciencia europeas, su objetivo es españolizar España en torno a tres ejes: (1) Castilla como eje de la construcción de la nación española; (2) la filosofía mística como máxima expresión del espíritu de la colectividad nacional; y (3) Don Quijote como símbolo del carácter nacional.

Europa queda reducida así a un conjunto de instrumentos externos, a una función mayéutica: es mera parturienta: "El porvenir de la sociedad española espera dentro de nuestra sociedad histórica, en la intra-historia, en el pueblo desconocido, y no surgirá potente hasta que le despierten vientos o ventarrones del ambiente europeo". Nuevamente, como en Ganivet, unas supuestas esencias custodiadas por los españoles de a pie han de hacerse realidad, aunque, al contrario de Ganivet, gracias al extrínseco estímulo europeo. España renacerá en su esencia, pero al menos en En torno al casticismo, en virtud de su simultánea europeización metodológica.

Adviene entonces la llamada pérdida de fe de Unamuno: "Su crisis religiosa de 1897 tuvo inmediatos efectos en su obra, y en su alejamiento de los ideales socialistas y de regeneración por medio de la ciencia y la europeización de España, que habían dominado su primera etapa productiva" (Beneyto, 1999: 101). La crisis también tiene otra consecuencia: "la tensión entre la razón y la voluntad de creer, entre la conciencia y el mundo externo, le conducirá a una dramatización permanente del problema de la identidad" (1999: 101). "La nueva versión del proyecto nacionalizador se irá perfilando como sustitución de la razón por la poesía y el mito" (1999: 105). Es decir, lo particularmente español ya no se descubrirá mediante lo generalmente europeo, sino gracias también a lo particularmente poético y lo míticamente español.

En términos generales esta crisis no altera los elementos fundamentales de su reflexión en En torno al casticismo. Lo único que cambia es la posición de Europa, que de ser parturienta de España acabará siendo, sencillamente..., objeto de españolización. España se erigirá en efecto para Unamuno en la depositaria del auténtico sentido de lo europeo: esto es, en la primacía de lo espiritual, frente al economicismo, industrialismo y demás vacuidades que erradamente se tienen por 
europeas (pero que producen ciertas comodidades que Don Miguel, a diferencia de Ganivet, no rechaza).

Y con Unamuno, Ortega como con Ganivet: si en 1940 lo ensalzó como hacedor del horizonte universal de la cultura española, antes lo había llamado "africanista" o "morabito".

Lo dicho hasta aquí de Unamuno lo asemeja tanto a Ganivet que no es preciso hacer repaso de cómo usa el bilbaíno las distintas categorías del juicio. Sabemos, sin embargo, que la identidad y la proyección de Unamuno fueron mucho más complejas y contradictorias que las del granadino, diferenciándose de éste al menos en dos elementos importantes: 1) el narcisismo de Unamuno es consciente y sistemático (es la base misma de su pensamiento) y 2) Unamuno era un liberal. Sí, junto a estas divagaciones sobre España que hemos resumido siguiendo lo planteado por Beneyto, Unamuno habría desarrollado, según Marichal, una reflexión de corte liberal en apariencia más consistente.

Unamuno habría defendido un liberalismo espiritual no católico. Hablaba de la necesidad de "descatolizar España" mediante una reforma religiosa que "el liberalismo es el que nos la puede traer". Se trataba según él de lograr el desarrollo de la conciencia de los españoles, que cada persona llegase a tener absoluta libertad espiritual. Se adscribía así al liberalismo de la llamada "escuela suiza" (Constant y demás) que identificaba el liberalismo "con la primacía de la conciencia": "un egotismo trascendental". En 1913, escribió: "como yo me siento yo, y quiero vivir entre semejantes, entre hermanos... quiero que sean yos los demás".

Y he aquí su característico "yoísmo": presente en sí mismo (en su autorepresentación, en su sentimiento trágico de la vida, en su agonismo, sus ideas sobre la muerte y la inmortalidad, en la estructura dialéctica de su pensamiento, etc.). Presente en las motivaciones tras sus reflexiones sobre España: como llegaría a decir en 1916, "Nosotros los ególatras del 98, no estábamos entonces dispuestos a vender el alma por un acta de diputado. Nos admirábamos a nosotros mismos, creíamos haber nacido para renovar la patria, para hacer de España el solar de los españoles, un pueblo de yos y no un rebaño de electores y contribuyentes". Presente, por último, en su idea del liberalismo, un liberalismo protestante en pos del hombre libre.

Como dice Marichal (1995: 123 y 125) "para él Europa era el atormentado Kierkegaard o el agónico Pascal" y anhelaba "la protestantización de la religión, como duda individual frente a creencias tradicionales [...], descatolizar" [... hacer una] "desamortización espiritual". Como dejó escrito en 1906: "En España descatolizar es españolizar". Buscaba la libertad de conciencia, entendiendo que la finalidad de la vida es hacerse, introversión mística mediante, un alma y alcanzar así la esencia personal, individual. Protestantismo en el método y como orden social, crisis de fe en el origen y misticismo castellano como meta..., ¡casi nada $!^{14}$..., y eso, así lo habría deseado Don Miguel, para todos los yos de España. 


\section{GANIVET Y UNAMUNO, TARDO-ROMÁNTICOS}

De lo apuntado hasta aquí, se desprende que, en verdad, ni Ganivet ni Unamuno tienen un proyecto de "europeización de España", sino de “españolización de España” y, si cabe, de Europa.

Donde mejor encajan sus respectivos pensamientos es en aquel debate iniciado en la década de 1870 sobre "la importancia relativa entre la ciencia y los valores espirituales". Debate, que en el ámbito del "tema de España" dará pie, a dos líneas de investigación: "de un lado, unos estudios hechos desde el punto de vista de las ciencias positivistas [por otro], una serie de obras que enjuician a España desde la atalaya de unas reflexiones culturales e históricas de corte espiritual y ético" (Inman Fox, 1990: 10). Y aquí se sitúan las obras de Ganivet y Unamuno, pero arrastrando consigo, o realizando tardíamente, el acervo de la tradición romántica europea.

Siguiendo a Fox (1990) podemos enumerar algunas características del romanticismo europeo presentes en el pensamiento del granadino y del bilbosalmantino: exaltación del individuo pero también de la sociedad orgánica, vuelta a la naturaleza, crítica al realismo, al industrialismo y al positivismo y apuesta por la imaginación y lo espiritual (y por el tormento personal, habría que añadir). A esto deben sumarse dos características esenciales (definitorias) del romanticismo que Fox no menciona: su historicismo y su función nacionalizadora.

Historicismo, espiritualismo, naturalismo, individualismo, nacionalismo, imaginación: todas estas constantes románticas se encuentran tras esa arqueología de las esencias a la que desde una evidente falta de rigor histórico, desde una insuficientemente fundada apuesta por determinados valores espirituales, desde cierto determinismo naturalista, desde una irresuelta tensión entre individuo monádico y espíritu colectivo, desde un empeño nacionalizador entendido como (contrastada pero infundada) diferenciación respecto al resto de naciones y desde una (confabuladora más que creadora) imaginación se entregan Ganivet y Unamuno.

Y lo hacen cumpliendo con otras constantes no ya del romanticismo sino del romántico hecho caricatura: la vanidad, el egotismo, el subjetivismo, la egolatría y el exhibicionismo aderezado todo ello con (afectadas o sentidas, poco importa) dosis de tormento y pesadumbre: una suerte de narcisismo masoquista.

El Marqués de Tamarón en su libro Rompimiento de Gloria gusta de llamar a Unamuno según el nombre botánico de una flor que al parecer brota en las sierras de Guadarrama y Gredos; el nombre de esa flor es verídico y como sigue: seudonarcisus confusus hispanicus.

Así, cabe aventurar concluir que Ganivet y Unamuno, en definitiva, proyectaron en sus respectivas ideas de España sus respectivas ideas (ya que no realidades) de sí mismos en una suerte de dialéctica circular entre la vanidad de la esencia y la esencia de la vanidad: es decir, idiotismo espiritual proyectado con misticismo, estado éste espiritual e idiosincrásico donde los haya..., y que, 
curiosamente, acaba configurando un programa nacionalizador más estático que extático.

Acabemos este epígrafe con una reflexión de Ortega sobre el misticismo: lo define como "la suplantación de este mundo por otro [...para añadir,] siempre me parece descubrir en él la intervención de la chifladura o de la mistificación". Curiosa manera de "hacer universal el horizonte de la cultura española" (1940) o "de sacudir los restos de provincialismo y resolverse a pensar y sentir en onda larga" (1927). Pasemos ahora a Ortega "und" Gasset, como he oído decir a algún malintencionado.

\section{ORTEGA Y GASSET, EL MUNDO COMO PLURALIDAD}

Ya han quedado esbozados en las páginas precedentes algunos elementos del planteamiento de Ortega sobre la "europeización de España": sincronización metodológica pero también temática, Europa como espacio cultural, necesidad de que lo español pueda enriquecer lo europeo, etc. Estos rasgos indicarían que las reflexiones orteguianas se alejarían de los esencialismos y españolismos ganivetianos y unamunianos para adentrase en los terrenos menos narcisistas de la "europeización de España" propiamente dicha.

Ocurre, sin embargo, que ese recurso de contraponer españolísimas esencias espirituales a desalmadas formalidades europeas también parece reproducirse en Ortega. Al menos así lo da a entender Beneyto. Según éste: “Ortega es europeísta a fuerza de españolismo, de su patriotismo español. La solución Europa está en función de España, de la recuperación de su historia y de su identidad, del intento de querer volver a dotar de sentido a la realidad España." (1999: 125).

Señala seguidamente Beneyto estas palabras de Ortega (década 1910): "no solicitemos más que esto: clávese sobre España el punto de vista europeo. La sórdida realidad ibérica se ensanchará hasta el infinito; nuestras realidades, sin valor, cobrarán un sentido denso de símbolos humanos. Y las palabras europeas que durante siglos hemos callado, surgirán de una vez, cristalizando en un canto. Europa, cansada en Francia, agotada en Alemania, débil en Inglaterra, tendrá una nueva juventud bajo el sol poderoso de nuestra tierra" (citado por Beneyto, 1999: 123). Por donde parece asomar el primer Unamuno que hacía de Europa la parturienta de España. Más palabras de Beneyto: "El impulso europeizador fue también orientado a conocer mejor la misma España, mediante la utilización de los métodos correspondientes a disciplinas como la filología, la historia del Derecho, la historia del arte y la historia general. Respondían todos estos trabajos al precepto que podría formularse así: <<sólo los españoles europeizados podrán descubrir a España $>>$. España había de ser explorada con instrumentos importados". En un esfuerzo por conseguir la sincronización de la actividad intelectual española con la transpirenaica. 
Uno de los propósitos de esta mayéutica consistiría para Ortega, siempre según Beneyto, en "crear un espacio público considerado inexistente hasta entonces en España, una actividad que Ortega entenderá como acción pública y no partidista, además de cómo una misión intelectual dominada por la idea de volver a dar sentido -filosófico, estético, nacionalizador a la cultura española". "El punto de partida será la consideración del problema nacional como un problema histórico. Y esto en un doble sentido: España no está a la altura de los tiempos porque no está a la altura de sí misma, principalmente porque no ha aceptado su historia, no se ha aceptado a sí misma: no es en plenitud, sólo late en las esencias de su entendimiento de la vida." (1999: 127)

El modo de alcanzar esa plenitud será la filosofía: gracias a la reflexión y el pensamiento, gracias a Europa. Se trata de europeizar España como medio para alcanzar un punto de vista español que sea capaz de proyectarse hacia Europa. Y una vez europeizada, ¿ser otra nación europea, una más?

No. Nuevamente, una Europa que se entiende en crisis podrá ser salvada por... España. ¿Con el acostumbrado misticismo? No: con el vitalismo orteguiano. Si Europa (la razón) es la solución al problema de España; España (la vida) es la solución al problema de Europa: razón y vida y su orteguiana síntesis: la razón vital. Cito de nuevo a Beneyto: para Ortega "España frente a Europa es radicalidad de lo real, es comprensión del ser como dramatismo, como plenitud de vida; la vida como algo previo y más amplio que la razón" (1999: 137). Plenitud a la que se accedería no ya con el misticismo senequista del granadino o con el misticismo protestante de Don Miguel, sino con la filosofía que "integre vida y razón” y que, siempre según la interpretación de Beneyto, permitiría, esta vez sí, una salida creativa que se proyecte sobre Europa (1999: 138 y ss.).

Pero, ¿que se proyecte, como da a entender Beneyto para salvarla, o simplemente para incorporarse al pensamiento moderno de Europa con una filosofía estrictamente española? Se trata de ofrecer la interpretación española del mundo en un esfuerzo de sincronización no por imitación sino por aportación de una filosofía del estar en el mundo como español; o como diría Marichal, añadiendo, no obstante, esa dimensión esencialista: "Una filosofía de ser español como interiorización de la tragedia de la humanidad" (1995: 125). Es decir, añadir la 'perspectiva' española a Europa o ¿se trata de revitalizar Europa con filosofía española, esto es, con Ortega (en otro ejercicio, ahora de alcance continental, de proyección de la propia vanidad?

Beneyto apuesta claramente por esta última interpretación (1999: 141): "sólo mirada desde España es posible Europa. Es más: España le revela a Europa una dimensión que le permanecía oculta y cuya carencia o debilitamiento le ha conducido al monstruo del idealismo. España como $<<$ proa del continente $>>$ revela a Europa que la vida, además de cultura, es drama, es lucha de un hombre con sus circunstancias".

Ocurre, sin embargo, que el pensamiento de Ortega es (1) poliédrico por cuanto aborda muchas temáticas desde distintas visiones metodológicas; y (2) es un 
pensamiento en evolución, según sean unas circunstancias españolas y europeas que cambiarán notablemente entre 1905 y 1955 y también según vaya desarrollando sus reflexiones filosóficas (dos primeros rasgos que permiten el que puedan darse interpretaciones variadas del pensamiento de Ortega); pero (3) es un pensamiento generalmente consistente, salvo, si hemos de creer en Beneyto, precisamente en ese esencialismo vitalista.

Sólo podemos aquí limitarnos a esbozar algunas líneas del pensamiento de Ortega siguiendo las categorías del juicio y el tema, la europeización de España, aquí consideradas.

Respecto a su juicio histórico. Ante todo conviene recordar que Ortega no sólo lo ejerce a título de intelectual sino que lo teoriza en cuanto filósofo a lo largo de su vida plasmando sus reflexiones en La razón histórica e Historia como sistema, entre otros textos (Cerezo, 1993), unas reflexiones que vienen a configurar una teoría consistente del devenir histórico como historia inteligible (al contrario de lo sostenido por Hegel, la historia construye la razón, no ésta a aquélla) que debe abrirse a los demás, a los alter egos históricos para alcanzar la comprensión del pasado, del presente y de uno mismo. En el orden práctico sus juicios históricopolíticos sobre España (en España invertebrada, por ejemplo) y sobre Europa ( $L a$ rebelión de las masas o Meditación sobre Europa) resultan paralelos y sin duda marcados por las circunstancias y las percepciones de su época. Conocida es su tesis sobre la española falta de vertebración, de nacionalización y de proyecto y sobre la necesidad de superar estas carencias gracias a la labor "cultural" de las elites. Tesis que ampliará al escenario europeo en La rebelión de las masas. Poco importa aquí discutir los méritos de estos juicios. Conviene, no obstante, señalar, primero, que respecto a España Ortega parte de la doble premisa metodológica de que (1) una de las principales carencias españolas es, en su época, la pobreza de la investigación historiográfica sobre el propio pasado y (2) que hay que ejercer el juicio histórico-político con responsabilidad, es decir, huye de las mistificaciones y de las conclusiones gratuitas. Segundo, el énfasis que Ortega da a la cultura en cuanto argamasa social; tercero, esta argamasa cultural es para Ortega constitutiva del espacio público, ya sea nacional o europeo; y cuarto, que Ortega, al proponer idénticas soluciones a los problemas de España y Europa está de hecho incluyendo a aquélla en ésta.

Respecto al juicio reflexivo. Podemos deducir los rasgos que Ortega atribuye a este juicio recordando su noción fenomenológica de la cultura y de la creación así como su idea de la hermenéutica. Cultura es para Ortega interpretación plural del mundo. Creación es aportación al mundo y hermenéutica es apertura a los demás.

Del juicio particularista. Ortega lo critica tanto en sus manifestaciones políticas en España en particular y en Europa en general ("la rebelión sentimental de las masas") como individuales, ante la prevalencia de ese ámbito llamado de lo social resultante de la mutua disolución (en Europa) o inexistencia (en España) de lo privado y lo público. 
Subyace en el pensamiento de Ortega una constante de orden fenomenológico: la pluralidad del mundo, ya que el mundo (muy especialmente Europa) sólo es porque es plural. Para Ortega, Europa (ya) es (y no debe por tanto llegar a serlo) el conjunto de las visiones que se dan en su seno, es un espacio de libertad creadora y de cultura y lo que España debe conseguir es aportar, como realidad europea, su propia perspectiva sobre Europa.

\section{A MODO DE SÍNTESIS}

Se advierte, pues, en el pensamiento de los dos primeros autores aquí tratados, y quizá también en el tercero, un afán por dar con la esencialidad de lo español: el secreto de la españolidad. Ganivet y Unamuno acometen una errática arqueología del "tipo español puro" que acaban confundiendo con el misticismo al que, equivocadamente, definen como 1) especialidad española (ya sea arabizante para Ganivet, o castellanizante para Unamuno) 2) presente en potencia en todos los españoles. Ortega, por su parte, apuesta por el vitalismo. Esta búsqueda de esencias se desarrolla sobre dos ejes: uno explícito, otro implícito y ambos descarrilados.

El explícito es el de la contraposición con "Europa": "España es diferente", ésta es la idea-fuerza. Y es distinta principalmente porque goza de espiritualidad frente a una "Europa" que los tres autores perciben como desalmada: secularizada, civilizada pero sin vida, industrializada y desnaturalizada, presa de la crisis de la razón y de los excesos del idealismo, etc. Los tres establecen esta contraposición entre "Europa" y "España", dos realidades que no manejan como tales realidades sino como conceptos, de ahí que los entrecomille. Para Ganivet, la contraposición es exclusión de lo europeo; para Unamuno es escisión; para Ortega, proyecto de síntesis. Pero la contraposición es absurda ya que se basa en una consideración del todo gratuita: que "Europa" carece de espiritualidad. Ahí están los Pascal, Kierkegaard, Schopenhauer, Nietzsche, Dostoievski, etc., y las distintas tradiciones teológicas y místicas, europeas. Unas tradiciones seguramente consistentes e intensas pero que pocos, salvo quizá los rusos, han querido radicar en la especialidad de un ser nacional, en un genio atávico y menos aún, convertir en proyecto redentor del continente.

El eje implícito es lo que puede denominarse "la recepción de las visiones de España de los europeos": los tres autores aceptan, elaboran y subliman los tópicos que sobre España han podido ir acumulando los europeos en sus interpretaciones del supuesto genio español; un catálogo de tópicos. Así, el español sería anarcoindividualista cuando en verdad es (como lamenta el propio Ortega) animal gregario; sería místico cuando en verdad se acomoda (como admite el propio Unamuno) en un catolicismo ritualizado; sería pasional y vital cuando en verdad (como advierte el propio Ganivet) es abúlico e indiferente. Pero poco importa la realidad: construyamos sobre el tópico, y sublímese en mito: el mito del Quijote, por ejemplo; sin duda más conveniente que el de la Carmen (de Bizet), demasiado 
chabacano. Más conveniente, ¿pero representativo?, ¿paradigmático? ¿Acaso los italianos han construido la imagen de sí mismos basándose en San Francisco de Asís, Orlando furioso o los teatreros Arlechino o Polichinella? ¿O los franceses recurriendo a Juana de Arco, Gargantua o Pantagruel o quién gastronómicamente fuere? ¿O los ingleses recreándose en las humorísticas y deportivas chanzas medievales narradas por Chaucer y universalizadas por Jonathan Swift y sus amigos del Scriblerus Club? ¿Qué ejercicio es ese de "esencializar el ser nacional" y hacerlo arquetípico? ${ }^{15}$ Sí, los españoles somos quijotescos, es decir, místicos, individualistas y pasionales..., jah! y toreros y jtodos por estos lares somos bailaores de flamenco, comemos paella y bebemos sangría!

¿Qué sentido tiene ir, conforme al título del libro de Marichal, en pos del "secreto de España"? ¿Acaso otros europeos se han dedicado a construir el alma de sus respectivos pueblos? Claro que lo han hecho: en la etapa romántico-nacionalista (y pudieron hacerlo sin dar cuenta de lo que otros pudieran haber dicho, más o menos gratuita y tópicamente, sobre sus respectivos pueblos). Ganivet, Unamuno y Ortega acometen en verdad (con un siglo de retraso respecto a, por ejemplo, los alemanes) ejercicios de nacionalización, claramente románticos en los dos primeros casos, más maduro y certero en el tercero. Ortega persigue en cierto modo aquello que Ernest Gellner define como esencia del nacionalismo occidental: "The essence of nationalism in the West is that High -literacy-linked culture becomes the pervasive membership-defining culture of the total society" (Gellner, 1994: 22). La relevancia pública de sus respectivos ejercicios radica, en última instancia, en el empeño formal que, consciente o inconscientemente, los motiva, no en sus contenidos. Me refiero al empeño nacionalizador que se produce en España (como apuntaba arriba al mencionar el artículo de José Álvarez-Junco) precisamente en esos años. Se ponen a la "altura de los tiempos": sí, de los tiempos "nacionalistas", de los tiempos que para gran parte de Europa "ya fueron" como diría Gombrowicz.

Más allá del empeño nacionalizador quedan los contenidos: gratuitos y del todo prescindibles en el caso de Ganivet; confusos y egocéntricos en Unamuno; muy dignos de atención en Ortega, cuando no huyen del "vital-españolismo".

\section{A MODO DE NUEVO INICIO}

Lo que cabe rescatar de Unamuno y considerar en Ortega son sus respectivos entendimientos de Europa (ahora sin comillas). Parcial e intuitivo en el bilbaíno, consistente y explícito en el madrileño, este entendimiento es, además de pertinente, europeo, es decir, no está condicionado por el punto de vista español de contraposición esencialista sino que atiende al fenómeno Europa tal como aparece en el ámbito de la cultura. Y al tener esta naturaleza al mismo tiempo fenomenológica y europea, el entendimiento sí puede aportar elementos para formular una idea de europeización de España desde la cultura. 
Me estoy refiriendo al "protestantismo liberal" de Unamuno, es decir, al fenómeno de la "construcción de la personalidad en el ámbito privado" y a la verbalización orteguiana de Europa como un espacio público de cultura y de ésta como interpretación plural del mundo. Conseguir en España un ámbito privado donde las personas construyan libremente (y lejos de arquetipos nacionales y gregarismos deterministas) sus personalidades, un espacio público exigente y una experiencia plural de la cultura significaría, si consideramos que se trata de unos fenómenos propios de la europeidad, haber europeizado España, al menos en el ámbito de lo cultural. ¿Se ha conseguido?

Recordemos que ese juego entre lo privado y lo público, entre lo particular y lo universal, entre la personalidad consistente y la sociedad exigente es el constitutivo del juicio reflexivo, del juicio creador no gratuito.

\section{NOTAS}

${ }^{1}$ Sobre las características del “ensayo español” véase (1991), El ensayo español hoy, Madrid, Ministerio de Cultura

${ }^{2}$ Son: (1) El juicio histórico/juicio político: o la capacidad de evaluar y seleccionar las experiencias del pasado (histórico) o del presente (político) (ya sean las propiamente españolas como las genéricamente europeas). (2) El juicio reflexivo: o la capacidad de crear nuevas normas. Este juicio tiene en su calificación una clara raigambre kantiana ya que fue Kant quien lo definió con estas palabras: "actúa siempre de tal forma que la máxima de tu voluntad pueda al mismo tiempo servir de principio para una legislación general". Esto es, el juicio reflexivo va de lo particular (la persona y su circunstancia) a lo universal ya sea éste precepto ético, ley positiva o canon estético: tiene una vis universalista. Pero tiene también estas otras cualidades: es creativo; la identidad del que lo formula es en su pulsión autónoma; tiene una dimensión ética (la del imperativo categórico "del estar de acuerdo con uno mismo) y una dimensión política presupuesta no ya sólo en la idea misma de acción sino también en uno de los requisitos mismos del juicio reflexivo: lo que Kant llama la "mente ampliada", es decir, la capacidad de "pensar poniéndose en el lugar de los demás", "suplantación", ésta, entendida como anticipación del diálogo con los demás y anticipación del acuerdo sobre el mundo. (3) El juicio determinativo: o la capacidad de aplicar normas preexistentes. Juicio, igualmente categorizado por Kant, que viene a ser el reverso del anterior. Es el juicio que va de lo universal a lo particular, de la norma preexistente al caso concreto. Sus cualidades son: a diferencia del reflexivo no es creativo sino aplicativo, fabricativo o reproductivo, su dimensión práctica es técnica, la identidad del que lo ejecuta no es constitutiva del juicio ya que el ejecutor actúa movido por una pulsión heterónoma que no precisa per se de introspección ética ni de proyección política ni de que se cumpla el imperativo categórico. Un caso extremo y paradigmático de "mentalidad determinativa" es la de Adolf Eichmann (vid Eichmann in Jerusalem, A Report on the Banality of Evil de Hannah Arendt). (4) El juicio particularista remite al concepto griego de idiotes, es decir, a quién no participa de la generalidad (de la polis) quedando bien atrapado (por intrínseca naturaleza) en, bien reducido (por extrínseca imposición) a su particularismo o idiotismo. Este juicio no alcanza lo universal bien porque se limita a recrearse en su idiosincrasia, bien 
porque no logra establecer vínculo con los demás (porque no pretende anticipar el diálogo con los demás ni el acuerdo sobre el mundo; porque el que lo formula no actúa o porque si actúa lo hace desde la imposición sin pretender alcanzar el acuerdo con los demás). El que lo formula puede cumplir para consigo mismo con el imperativo categórico pero se queda en eso: sólo proyecta su propia identidad.

3 Parece, incluso, que el propio Ortega inventó la expresión "Generación del 98" en 1913, véase al respecto la interesante nota 1 en Marichal, 1995: 329

${ }^{4}$ Véase lo que Garagorri (1985: 227-9) dice de la primera (y rechazada) tesis de Ganivet titulada "España filosófica contemporánea". La segunda y aceptada tesis versó sobre la recepción del sánscrito en la lengua castellana.

${ }^{5}$ Ganivet dirá incluso "No amo la acción ni la contemplación..., cuando se es cínico hay que vivir en el tonel de Diógenes, y cuando se es escéptico hay que dejarse atropellar por el tren que viene resoplando y morir creyendo que el tren es una ficción" (citado por Trapiello, 1997: 75).

${ }^{6}$ Véase Garagorri, 1985: 226 y nota 12.

${ }^{7}$ Se modifica el título del famoso libro de Rostov.

${ }^{8}$ No obstante su salvífica presunción, Dostoievsky llegó a ser, si no el evangélico redentor de Europa ("antes Cristo que la verdad", decía), uno de los grandes creadores de la literatura universal. Cabe preguntarse cuál es la consistencia (incluso la fuente de la existencia) de esos motivos españoles que, según Marías, han de sacar adelante la mente europea.

9 Se equivoca Beneyto cuando argumenta (1999: 71) que "su [de Ganivet] toma de conciencia del mal español se producirá con la primera inmersión, durante la época como vicecónsul en Amberes (1892-1895), en la crisis finisecular europea”. Beneyto, siguiendo ciegamente la interpretación orteguiana de la Generación del 98 como preocupación colectiva por "europeizar España", da equivocadamente por sentado que los miembros de dicha Generación iniciaron sus reflexiones en torno al "tema de España" tras vivir experiencias europeas que les servirán de referencia. Así, en el caso de Costa tras su visita a la Exposición Universal de París en 1867 y en el de Unamuno, sus muchas lecturas de autores europeos: como si todos hubieran tenido que hacer sus respectivos caminos a Marburgo. Como veremos, Ganivet siente por Europa ante todo desprecio, otro tanto puede decirse del segundo Unamuno.

${ }^{10}$ Ganivet demuestra desconocer los debates sobre el concepto de nación que venían desarrollando, sobre todo, alemanes y franceses (Renan).

${ }^{11}$ Usamos justamente aquí esos dos conocidos conceptos orteguianos: alteración y ensimismamiento.

12 A don Ángel le "Manca finezza" como habría dicho el maquiavélico italiano (Giulio Andreotti): ¿será mero producto de una "sub-cultura de pacotilla" en palabras de Bruno Schulz?

${ }^{13}$ Las cartas que se intercambiaron se han publicado bajo el título El porvenir de España (Espasa-Calpe).

14 “!Casi nada!” diríamos por estos lares, ¿en tono místico, aprés tout? El ¿teatrero? italiano diría "Che programma!”; el ¿pantagruélico? francés, "Quel menu!”, el ¿humorístico y deportivo? inglés diría "Nice prospect!".

${ }^{15}$ John Arbuthnot, el amigo de Jonathan Swift, lo hizo con su History of John Bull, pero con tremenda carga satírica. 


\section{BIBLIOGRAFÍA}

ÁLVAREZ JUNCO, J. (1997): “El nacionalismo español como mito movilizador. Cuatro guerras”, en CRUZ, R. y PÉREZ LEDESMA, M. (eds.), Cultura y movilización en la España contemporánea, Madrid, Alianza.

ARENDT, H. (1958): The Human Condition, Chicago, University of Chicago Press.

- (1963): Eichmann in Jerusalem, A Report on the Banality of Evil, London, Penguin Books.

BENEYTO, J. M. (1999): Tragedia y Razón. Europa en el pensamiento español del siglo $X X$, Madrid, Taurus.

CEREZO, P. (1993): "La razón histórica en Ortega y Gasset”, en MATE, R. (ed.), Filosofía de la Historia, Madrid, Trotta-CSIC.

GARAGORRI, P. (1985): La filosofia española en el siglo XX. Unamuno, Ortega, Zubiri, Madrid, Alianza.

GELLNER, E. (1994): Conditions of Liberty, Civil Society and its Rivals, London, Hamish Hamilton.

INMAN FOX, E. (1988): Ideología y política en las letras de fin de siglo (1898), Madrid, Espasa-Calpe.

— (1990): [1940], “Introducción”, en GANIVET, A. Idearium Español, Madrid, EspasaCalpe.

LAÍN ENTRALGO, P. (1983): [1947], La generación del noventa y ocho, Madrid, EspasaCalpe.

MARÍAS, J. (1996): [1985], España inteligible, Barcelona, Círculo de Lectores.

- (2001): Ser Español, Barcelona, Planeta.

MARICHAL, J. (1995): El secreto de España. Ensayos de historia intelectual y política, Madrid, Taurus.

TRAPIELLO, A. (1997): Los nietos del Cid. La nueva edad de Oro de la literatura española (1898-1914), Barcelona, Planeta. 